\title{
DYNAMICS IN THE DEVOLOPMENT OF DONKEY POPULATION IN
} BULGARIA

\author{
R. Vlaeva ${ }^{1}$, G. Barzev ${ }^{1}$, S. Georgieva ${ }^{2}$, I. Ivanova ${ }^{3}$ \\ ${ }^{1}$ Department of Non-ruminant and Other Animals, Faculty of Agriculture, Trakia University, \\ Stara Zagora, Bulgaria \\ ${ }^{2}$ Department of Genetics, Breeding and Reproduction, Faculty of Agriculture, Trakia University, \\ Stara Zagora, Bulgaria \\ ${ }^{3}$ Student - Department of Non-ruminant and Other animals, Faculty of Agriculture, Trakia University, \\ Stara Zagora, Bulgaria
}

\begin{abstract}
The aim of the recent study was to trace back the development of the donkey population in Bulgaria for the period $1950-2015$. For that purpose the data from the National Statistic Institute and FAO was processed and other sources related to the problem were analyzed. Donkeys in Bulgaria used to be a comparatively large share of the traction power animals in the past, with the occurance of the social and economical changes after 1990 their number was dramatically reduced. This process is most noticeable after 2000, when for five year period until 2005 the donkey population in Bulgaria drops down from 207000 to 90000 individuals, as in 2013 this number falls down to 35000 according to FAO.
\end{abstract}

Key wards: donkey, population, development, traction power

\section{INTRODUCTION}

The current stage of development of the agricultural sphere in Bulgaria is distinguished with parcelled out land after finalization of the repossession process, outdated agricultural equipment and buildings, that do not meet the EU requirements (1). According to the Ministry of agriculture in Bulgaria there are 5,1 million hectares of land for agricultural purposes owned by 2,4 million owners. This explain why the draught animal power is still used for land cultivation.

The number of donkeys worldwide is 41 million (2), but some authors presume that this number is much higher than the reported in the official statistics (3). The number of donkeys in the different countries depends of the economical status of the nation, availability of agricultural land, fuel prices, and their popularity as a domestic animals (4).

The Domestic Animal Diversity Information System hosted by FAO reports 189 breeds of donkeys worldwide in 2011. In 1995 the total number of donkey breeds reported is 77 and in

\footnotetext{
*Correspondence to: Radka Vlaeva, Department of Non-ruminant and other animals, Faculty of Agriculture, Trakia University, 6000 Stara Zagora, Bulgaria, email: rvlaeva@gmail.com
}

2000 this number is 97 . The fast growing number of donkey breeds is mostly due to the fact that they need to be identified and registered for different FAO projects. For example until 1990 only one donkey breed Poitou is known in France but on later stage six more breeds are officialy recognized (5).

In Bulgaria donkeys represent comparatively large part of the traction animal power. Parallel with the establishment of the national studs, donkey breeding sections were organized in the studs mainly to provide breeding jacks and working animals for the rural population. In our country there is a profound information regarding the biological characteristics of the donkey, but not much information concerning the historical development in Bulgaria (6). Between 1975 - 1995 the greatest number of animals used for their draught power in agriculture are donkeys (7). They represent nearly $70 \%$ of the total number of working animals in the country. After that period of time the number of donkeys is considerably reduced not only in Bulgaria, but this trend seams to spread all over Europe.

Having in mind the considerable presence of donkeys in agriculture and everyday life of the population in Bulgaria the aim of the recent 
study was to determine the status and dynamics in the development of donkeys population at the end of 20-th and the beginning of 21-st century.

\section{MATERIAL AND METHODS}

Subject of the recent study was the donkey population in Bulgaria for the 65 year period, between 1950 and 2015. For the appointed period of time the data from the National Statistical Institute of Bulgaria and FAO was processed. Analysis of the bibliographical sources related to the problem was made.

\section{RESULTS AND DISCUSSION}

The ancestors of the present-day donkey are the Nubian wild ass and Somali wild ass. Remains of domesticated donkey give us information for the co-existence of man and donkey from ancient times (4th century BC). Compared to the sheep, goats and cattles the domestication of the donkey happened on a significantly later stage in time. Nevertheless the domesticated donkey gives mobility to the shephaerds tribes and changes the customs of breeding already domesticated animals. As a means of transport and for its wider use in man`s everyday life, the donkey spread all over the world.

Nowadays the number of donkeys worldwide is more than 41 million, which compared to the number of horses (around 65 million) is a significantly large number (Table 1).

Table 1. Distribution of donkeys in different regions

\begin{tabular}{|l|c|c|}
\hline \multicolumn{1}{|c|}{ Region } & Number of donkey breeds & $\begin{array}{c}\text { \% of world population } \\
\text { (more than 41 million) }\end{array}$ \\
\hline Africa & 26 & 26,9 \\
\hline Asia & 32 & 37,6 \\
\hline Europe /Caucasus & 51 & 3,7 \\
\hline Latin America / Caribbeans & 24 & 19,9 \\
\hline Near and Middle East & 47 & 11,8 \\
\hline North America & 5 & 0,1 \\
\hline
\end{tabular}

The largest donkey population is recorded in China - 11000 000, followed by Pakistan, Ethiopia and Mexico. Some authors believe that the number of donkeys worldwide is much larger than the reported in the official statistics. The distribution of donkeys in different regions shows signifficant difference. Greatest number of donkeys is reported in Asia, Africa and Latin America and the lowest number is observed in North America and Europe. It is interesting to point out that in the region of Europe and Caucasus the number of donkeys is not that big, but there is large diversity of breeds registered in that region, which probably is due to the fact that in Europe there is a well developed identification system for Equidae.

In Bulgaria donkey breeding sections were established alongside with the development of horse stud farms. Some of the first section specialized in breeding donkey were located near Yambol, Nova Zagora, Plovdiv and Samokov (Picture 1). Main objectives of these sections were reproduction of donkeys and production of mules as working animals.

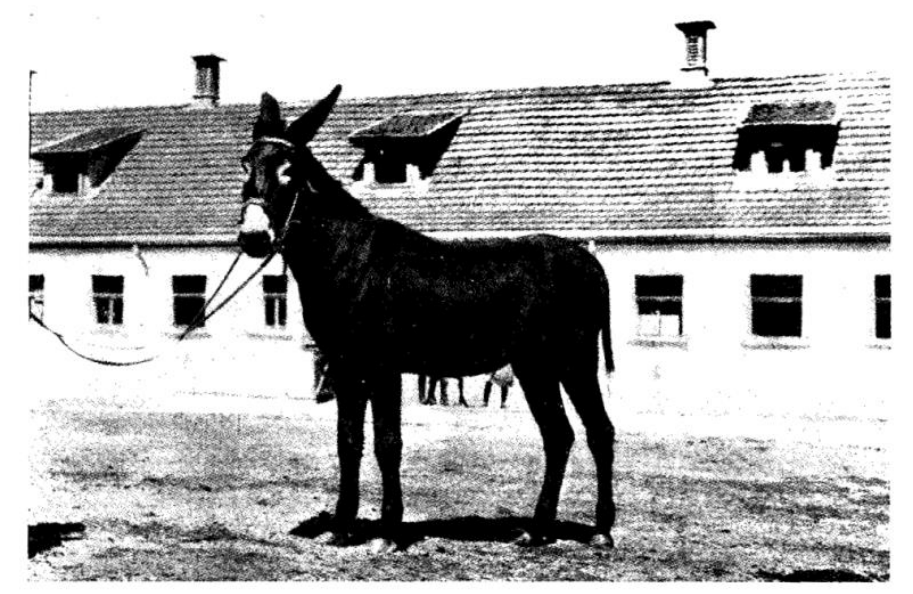

Picture 1. Elio, a Martina Franca jack imported from Italy in 1933. Used for breeding in the donkey section near Samokov. (Picture by Report of the state breeding stations 1929-1396). 
During the 20 year period between 1975 1995 the largest number of aminals used for tracking power in the country were donkeys. In the beginning of $20^{\text {th }}$ century the number of donkeys is significantly lower than the number of horses - 494557 horses and 107098 donkeys. As we follow the dynamics in the development of both populations it is clear that the number of horses is growing until 1939 and after that year it lowers dramatically, while the number of donkeys is growing progressively until 1985 and after that it decreases (Table 2)
The number of donkey decreases dramatically after 2000. In five years time between $2000-$ 2005 donkey population in Bulgaria lower its number double, from 207000 in 2000, to 90000 in 2005. This trend is observed and during the last decade, as for 2013 the number of donkeys in the country reported by FAO is barely 35000 . The same progressive decrease in numbers is observed in horse population as well.

Table 2. Number of horses, donkeys and mules in Bulgaria for the period $1900 / 2013$.

\begin{tabular}{|c|c|c|c|}
\hline Year & Number of horses & Number of donkeys & Number of mules \\
\hline $1900-1905$ & 494557 & 107098 & 8889 \\
\hline 1934 & 531452 & 180703 & 36660 \\
\hline 1939 & 614406 & 169390 & 34335 \\
\hline 1952 & 471064 & 197113 & 36416 \\
\hline 1960 & 333813 & 241676 & 34037 \\
\hline 1975 & 137351 & 317077 & 30925 \\
\hline 1985 & 118089 & 348769 & 27196 \\
\hline 1990 & 118902 & 328587 & 21751 \\
\hline 1995 & 133045 & 275627 & 15855 \\
\hline 2000 & 141025 & 207689 & 15539 \\
\hline 2005 & 135000 & 90000 & 9500 \\
\hline 2010 & 112000 & 45000 & 4000 \\
\hline 2013 & 58000 & 35000 & 3000 \\
\hline
\end{tabular}

The strongly reduced number of Equidae give us notion for the reduced necessity of using donkeys as draft animals. Presumably the reason for that could be the fast spread of small farm equipment in the farm yards and the process of depopulation of the rural areas. Important factor influencing dramatic reduction of donkeys in Bulgaria is the absence of a system or a procedure that can organize and control the breeding process. Recently in the country there are very few donkey breeding farms which in our opinion is insufficient.

\section{CONCLUSION}

The number of donkey population in Bulgaria after 1990 is strongly reduced, as until 2000 their number drop dramatically with nearly 150000 individuals. For the period between 2005 - 2013 this trend is even more visible, as in 2013 is reported the lowest number of donkeys in the country -35000 individuals.

Some of the factors affecting the reduction of the donkeys are the process of depopulation of the rural areas, fast spread of small farm equipment in the farm yards and absence of a procedure that can organize and control the breeding process.

\section{REFERENCES}

1. Popov V., Karova A., Biological Agriculture, Academic Publishing, Agricultural University, Plovdiv.

2. Waltraud K., Grunenfelder, H.P., Broxham, E., Donkey Breeds in Europe: Inventory, Description, Need for Action, Conservation; Report 2007/2008. St. Gallen, Switzerland: Monitoring Institute for Rare Breeds and Seeds in Europe, 2008.

3. Starkey P. and Starkey, M., Regional and World trends in Donkey Populations, Animal Traction Network for Eastern and Southern Africa (ATNESA), 1997.

4. Blench R., The History and Spread Of Donkeys in Africa, Animal Traction Network for Eastern and Southern Africa (ATNESA), 2000.

5. Berard L., Cegarra, M., Djama, M., Louafi, S., Marchenay, Ph., Roussel, B., Verdeaux, F., Biodiversity and Local Ecological Knowledge in France Institut National de la Recherche Agronomique; Centre de Cooperation Internationale en Recherche Agronomique pour le Developpement; Institut du Developpement Durable et des Relations Internationales; Institut Francais 
de la Biodiversite. ISBN 2- 915819-06-8, p.109, 2005.

6. Karaivanov R., Koychev K., Barzev G., Karadzhov T., Horse and donkey breeding, ISBN 945-05-03-07-8, Iusautor. Sofia, 1995.

7. Gadzhev S., All about the donkey, ISBN 954-8180-30-8, Stara Zagora, 1997.
8. Barzev G., The present situation and prospects for use of draught animal power in Bulgaria. Draught Animal Power in Europe and the Mediterranean Basin. Zaragoza, 45, 3-9, 1995.

9. Report of the state breeding stations for the period 1929 - 1936, Sofia, 1939.

10.http://www.fao.org 